\title{
Tapping into the Power of Twitter: A Look at Its Potential in Canadian Health Libraries
}

\author{
David C. Waddell \\ MLIS Candidate \\ School of Library, Archival and Information Studies \\ University of British Columbia \\ dcwaddell@gmail.com \\ Morgan Barnes \\ MLIS Candidate \\ School of Library, Archival and Information Studies \\ University of British Columbia \\ mogochud@gmail.com \\ Stefan Khan-Kernahan \\ MLIS Candidate \\ School of Library, Archival and Information Studies \\ University of British Columbia \\ skhanker@gmail.com
}

\section{Abstract}

Health libraries can use Twitter as an effective system for measuring the success of their social media strategies with the application of the right tools.

\section{Keywords}

professional development; Twitter metrics; social media; strategic planning

\section{Introduction}

In health libraries it is becoming increasingly important to recognize and understand user interactions and expectations. Research suggests that more and more patients will begin to rely on online resources to receive health information. In response, many health organizations have turned to social media and micro-blogging services to try to meet those needs. The ease of posting and sharing information on Twitter makes it an essential tool for health libraries to reach their users. However, libraries that lack systematic metrics for measuring success can find themselves pouring precious resources into social media upkeep without knowing if they are promoting their strategic vision. In this paper we demonstrate how simple metrics for evaluation can be used to gauge the effectiveness of a library's Twitter usage. 
In order to ascertain the current best practices, the authors reviewed articles discussing Twitter use in health libraries over the last few years. Using that information, an environmental scan was then conducted in order to discover how health libraries in Canada could best use Twitter. Examination of the resulting data suggests how metrics can provide evidence for the success of library Twitter use and how that success can mean deeper, more meaningful relationships with patient communities. The paper presents a variety of possible approaches that weigh the pros and cons, so that each library can implement better practices that match the unique strategic goals of its organization.

\section{Literature Review}

Twitter is a micro-blogging service with tremendous potential as a communication tool (Terry 507). Since patients are turning more and more to online communities and tools to get information about symptoms and general health maintenance, Twitter is a great way for health libraries to join patients in these online spaces (Hesse 2622). However, how Twitter should ultimately be used is up for debate, as the official usage policies and professional standards used by libraries can vary on the subject of social media (Chretien 566). Twitter also offers benefits by generally "[enhancing] community outreach" and providing "employee relation improvements" (Sarringhaus 236).

Along similar lines, health librarians such as Dean Giustini have suggested that Twitter can be used to reach new audiences and improve communication between patients and health providers ("Twitter: an Introduction" 12). The latter is a point echoed by analyst David Stuart. He suggests that the best Twitter use occurs when messages address patrons directly in conversation, as opposed to constantly sending out general institutional messages to the public at large (47). Current research has shown library Twitter accounts are used primarily as a "marketing and customer relationship manager" (Cuddy, Graham, and Morton-Owens 321), so there is definitely room for increasing direct engagement.

Hackworth argues that social media is not just about marketing but is also a powerful tool for developing deeper relationships with patrons (9-10). American patient advocate and researcher John Sharp points out that there are many strategies available for libraries that want to move beyond pure marketing. Once such strategy, known as social media "branding", was used by the Cleveland Clinic, whose staff saw social media as an "opportunity to innovate how it presents its brand and to engage patients and the community in learning about health" (Sharp 29). Its official policy aims to encourage employee participation and creativity online while cautioning staff contributors about the potential consequences of the improper use of social media (Sharp 29).

Between March 2012 and August 2012 we examined tweets by major health organizations with libraries, such as Fraser Health (Surrey, BC), Mount Sinai (Toronto, 
$\mathrm{ON})$, Vancouver Island Health Authority (BC), and the Montreal Children's Hospital (QC), to determine how they use Twitter and the impact on information service delivery.

We based our criteria for examining the use of Twitter at health organizations with libraries on the research by O'Moore-Klopf, Stuart, Hagman, and Cuddy, Graham, and Morton-Owens. O'Moore-Klopf's research demonstrates that health libraries can use Twitter more effectively by engaging followers or by starting interactive conversations with them (O'Moore-Klopf 183). Stuart influenced our research by pointing out that Twitter possesses an excellent application-programming interface (or "API") that allows the information within Twitter to be accessed and analyzed fairly easily by many different tools and software (Stuart 45). As Stuart suggests, we use a service called "Foller.me" to collect analytic data from Twitter. The Foller.me service generates statistics on how Twitter accounts interact with their users, which was invaluable to our research. This data is not otherwise available using Twitter's basic services.

However, using the best software for Twitter alone is not enough. High quality content must also be provided. Jessica Hagman, who has written about the best practices for starting a library Twitter account, suggests that libraries should share more information on Twitter that is specifically relevant to that library's users (82). A report outlining the potential use of Twitter in health libraries, written by Cuddy, Graham, and MortonOwens, focuses on the topics of tweets, their regularity and style, as well as strategies to encourage users to engage the library and post tweets that interact with the library Twitter account. Using this research, as well as research by Chretien, Giustini, and Sarringhaus, we have determined the following criteria for examining the use and impact of twitter in health libraries:

- Usability - What tools are available to help facilitate the use of the Twitter platform, and what features, if any, make them advantageous for the health library to adopt?

- Branding - What does the Twitter platform offer that allows the Library to establish itself as a brand? Cuddy et al. recommend the use of a library logo and name that followers will remember in order to create a strong sense of branding (322). Apart from the profile logo, are account names and hashtags being used to build the identity that the library wants the community to see?

- Content Insights - Does the Twitter software/platform used by a library offer sufficient functions or access tools to allow librarians to collect data about the most popular hashtags, tweets most retweeted, etc.?

- Exposure and Reach - 'Exposure' is the total number of views that a tweet generates on the twittersphere (Neiger et al. 164). How does the librarian keep track of this, as well as follow measures such as the number of followers, the rate of change in the number of followers, etc.?

- Engagement - Is the library mentioning other Tweeters? Are they being mentioned and retweeted in return, and how is this being tracked? 
As our paper focuses on Canadian health libraries, we used an online wiki that discusses health library concerns, called the HLWIKI, to compile a list of all Canadian health libraries and health organizations that tweet. We did not use data from librarians' personal accounts, since they sometimes included tweets from their personal lives. We gathered data on the 100 most recent tweets from each health organization account we observed. As not all Twitter accounts were active at the time of data gathering, we narrowed our data set to eight Canadian hospitals with libraries that use Twitter. Each hospital Twitter account was analyzed using the Foller.me service. We then used the statistics generated by Foller.me, the results of which can be seen in Tables 1, 2, and 3, and combined them with the best practice criteria identified in our literature review to evaluate our results.

Table I - Content Analysis

\begin{tabular}{|c|c|c|c|c|}
\hline Hospital & $\begin{array}{l}\text { Hours of } \\
\text { Use }\end{array}$ & $\begin{array}{l}\text { Use of } \\
\text { Community } \\
\text { Tags }\end{array}$ & $\begin{array}{l}\text { Use of Brand/Reach } \\
\text { Tag }\end{array}$ & $\begin{array}{l}\text { Use of Illness } \\
\text { Tags }\end{array}$ \\
\hline $\begin{array}{l}\text { Fraser Health } \\
\text { (@fraserhealth) }\end{array}$ & $\begin{array}{l}7 \mathrm{am}- \\
4 \mathrm{pm}\end{array}$ & $\begin{array}{l}\text { Yes } \\
\text { \#chilliwack, } \\
\text { \#surreybc, } \\
\text { \#southsurrey, } \\
\text { \#newwest }\end{array}$ & $\begin{array}{l}\text { Yes } \\
\text { \#worldnotobaccoday, } \\
\text { \#elderabuse, } \\
\text { \#fitness }\end{array}$ & $\begin{array}{l}\text { Yes } \\
\text { \#heartdisease, } \\
\text { \#renal }\end{array}$ \\
\hline $\begin{array}{l}\text { Montreal Children's } \\
\text { (@hopitalChildren) }\end{array}$ & $\begin{array}{l}8 \mathrm{am}- \\
5 \mathrm{pm}\end{array}$ & No & $\begin{array}{l}\text { Yes (\#safety, } \\
\text { \#childdevelopment) }\end{array}$ & $\begin{array}{l}\text { Yes (\#suicide, } \\
\text { \#earinfections) }\end{array}$ \\
\hline $\begin{array}{l}\text { Humber River } \\
\text { (@HRRH_Foundation) }\end{array}$ & $\begin{array}{l}8 \mathrm{am}- \\
4 \mathrm{pm}\end{array}$ & No & No & No \\
\hline $\begin{array}{l}\text { Foundation Children } \\
\text { (@mtlchildrens) }\end{array}$ & $\begin{array}{l}8 \mathrm{am}- \\
6 \mathrm{pm}\end{array}$ & $\begin{array}{l}\text { Yes } \\
\text { (\#montreal, } \\
\text { \#thecity) }\end{array}$ & $\begin{array}{l}\text { Yes, very good } \\
\text { example of use, } \\
\text { specific to programs } \\
\text { offered } \\
\text { (@sianbradwellfund, } \\
\text { \#kiliforthechildrens } \\
\text { \#skiforthechildrens) }\end{array}$ & Yes (\#cancer) \\
\hline $\begin{array}{l}\text { Mount Sinai } \\
\text { (@mountsinai) }\end{array}$ & $\begin{array}{l}9 a m- \\
5 p m\end{array}$ & $\begin{array}{l}\text { Yes (\#toronto, } \\
\text { \#ontario) }\end{array}$ & $\begin{array}{l}\text { Yes (\#mountsinai, } \\
\text { \#earthhour, } \\
\text { \#chefchallenge) }\end{array}$ & $\begin{array}{l}\text { Yes (\#diabetes, } \\
\text { \#cancer) }\end{array}$ \\
\hline $\begin{array}{l}\text { Providence Health } \\
\text { (@Providence_Hlth) }\end{array}$ & $\begin{array}{l}1 \mathrm{pm}- \\
10 \mathrm{pm} \\
\text { (instances } \\
\text { at } \\
\text { midnight, }\end{array}$ & $\begin{array}{l}\text { Yes (\#canada, } \\
\text { \#princegeorge) }\end{array}$ & $\begin{array}{l}\text { Yes (\#healthfest, } \\
\text { \#worldkidneyday, } \\
\text { \#hearthealthy) }\end{array}$ & $\begin{array}{l}\text { Yes } \\
\text { (\#heartdisease, } \\
\text { \#aids) }\end{array}$ \\
\hline
\end{tabular}




\begin{tabular}{|l|l|l|l|l|}
\hline & $\begin{array}{l}\text { 9am and } \\
11 \mathrm{am})\end{array}$ & & \\
\hline $\begin{array}{l}\text { Sunnybrook Hospital } \\
\text { (@SunnybrookHSC) }\end{array}$ & $\begin{array}{l}\text { 8am - } \\
1 \mathrm{am}+\end{array}$ & Yes (\#toronto) & $\begin{array}{l}\text { Yes } \\
\text { (\#nutritionmonth) }\end{array}$ & $\begin{array}{l}\text { Yes } \\
\text { (\#depression, } \\
\text { \#breastcancer) }\end{array}$ \\
\hline $\begin{array}{l}\text { Vancouver Island } \\
\text { (@VanlslandHealth) }\end{array}$ & $\begin{array}{l}\text { 9am - } \\
\text { 5pm } \\
\text { (instances } \\
\text { at 7pm, } \\
10 \mathrm{pm}- \\
\text { midnight) }\end{array}$ & $\begin{array}{l}\text { Yes } \\
\text { (\#vancouver) }\end{array}$ & $\begin{array}{l}\text { Yes (\#stigma2012, } \\
\text { \#viha) }\end{array}$ & $\begin{array}{l}\text { Yes (\#arthritis, } \\
\text { \#ecoli, \#stroke, } \\
\text { \#hepc) }\end{array}$ \\
\hline
\end{tabular}

Table II - Reach \& Engagement Analysis

\begin{tabular}{|l|l|l|l|l|l|}
\hline $\begin{array}{l}\text { Hospital } \\
\text { (follower ratio }\end{array}$ & Replies & $\begin{array}{l}\text { Mentioned } \\
\text { People }\end{array}$ & $\begin{array}{l}\text { Hashtagged a } \\
\text { Topic, etc. }\end{array}$ & $\begin{array}{l}\text { Follow On } \\
\text { Link to a } \\
\text { website }\end{array}$ & $\begin{array}{l}\text { Retweeted } \\
\text { Other Person's } \\
\text { Content }\end{array}$ \\
\hline $\begin{array}{l}\text { Fraser Health } \\
(8.98)\end{array}$ & 16 & 71 & 34 & 72 & 22 \\
\hline $\begin{array}{l}\text { Montreal } \\
\text { Children's } \\
(1.09)\end{array}$ & 36 & 65 & 45 & 46 & 3 \\
\hline $\begin{array}{l}\text { Humber River } \\
(1.69)\end{array}$ & 9 & 23 & 0 & 76 & 14 \\
\hline $\begin{array}{l}\text { Foundation } \\
\text { Children (1.48) }\end{array}$ & 24 & 66 & 32 & 47 & 14 \\
\hline $\begin{array}{l}\text { Mount Sinai } \\
(2.48)\end{array}$ & 4 & 35 & 37 & 75 & 9 \\
\hline $\begin{array}{l}\text { Providence } \\
\text { Health (1.5) }\end{array}$ & 9 & 73 & 64 & 51 & 60 \\
\hline $\begin{array}{l}\text { Sunnybrook } \\
\text { Hospital (1.88) }\end{array}$ & 70 & 78 & 33 & 39 & 1 \\
\hline $\begin{array}{l}\text { Vancouver } \\
\text { Island (32.98) }\end{array}$ & 7 & 55 & 26 & 82 & 34 \\
\hline
\end{tabular}


Table III - Tools and Platforms Used

\begin{tabular}{|l|l|}
\hline Hospital & Social Media Management Tool(s) or Platform(s) \\
\hline Fraser Health & HootSuite \\
\hline Montreal Children's & TweetDeck \\
\hline Humber River & HootSuite \\
\hline Foundation Children & HootSuite \\
\hline Mount Sinai & TweetDeck \\
\hline Providence Health & TweetDeck \\
\hline Sunnybrook Hospital & HootSuite, TweetDeck \\
\hline Vancouver Island & HootSuite \\
\hline
\end{tabular}

\section{The Analysis and Recommendations}

After performing an environmental scan, the data was relatively easy to gather. Many tools exist that allow for in-depth analysis of the criteria described in the evidence section. It should be emphasized that the methods applied in this study could easily be replicated by other librarians using their own data.

\section{Usability}

Before adopting any new social media platform, health librarians should make some attempt to understand how the platform (the software you use to access Twitter) will affect their daily workflow (Terry 508). Twitter does not offer multiuser accounts. As a result, when several people tweet from within the same organization it can create challenges in scheduling individual times for account access or managing how users track their actions. For example, one solution could be that staff notify others on the team of the contents of their tweet, so that the same information is not broadcasted twice.

Social media management tools, such as SproutSocial and HootSuite, provide scheduling, task assignment, reporting, and analytic tools for frequent users. These services assist multiple users in building workflows for an account and maximizing the usability of the service (Felix). The popularity of these tools among health libraries can be observed in Table III. All of the organizations we examined have adopted at least one of these tools to help monitor their social media presence. 


\section{Branding}

Cuddy et al. recommend the use of a library logo and name that followers will remember in order to create a strong brand (322). Apart from the account profile, the use of branding in content via hashtags is useful in building the library's digital brand and identity as well as in identifying who the library sees as its 'community'. This idea is represented in Table I, and the data reveals that some health organizations do not engage in this kind of promotion, while others do it with varying frequency. Strong examples of branding and promotion can be seen in the Foundation Children account (@mtlchildrens), which uses hashtags for each program it promotes, and in Fraser Health (@fraserhealth), which frequently uses both location and branding tags.

\section{Gaining Content Insight}

Gaining insight into tweets and tweet content can be done with analytical tools and data-mining methods. Twitter metrics typically cover topics such as keyword density, use of hashtags, tracking number of retweets, and looking at what time of day tweets are recirculated. This information can be used to adjust staff workflow and to respond to trending medical topics identified by your community.

Careful tracking and planning will ensure higher impact for your Twitter use, and is helpful in gaining user feedback. One insight from looking at the data from these health libraries is that tweeting is an activity that can be delegated as a task for library assistants and other workers (See Table I). As long as adequate training and planning is provided, tweeting does not have to be performed by a professional librarian.

\section{Exposure and Reach}

'Exposure' is the total number of views that a tweet generates on the twittersphere (Neiger et al. 164). This is measured by the sum of those who receive tweets by following a particular account, or conversely those who get secondary exposure from retweets and mentions in new posts. The notion of 'reach' differs from exposure and is defined as those who perform some action because of the content, such as retweeting (Neiger et al. 164). While exposure is not easily measured, metrics can include monitoring the number of followers and the rate at which an account attracts new followers. Alternative dimensions for reach might include the demographics of users and their geographic distribution, which can be measured through third party tools such as SproutSocial.

In Table II, we can see that @VanIslandHealth (Vancouver Island Health) has a follower ratio of 32.98: meaning that for every 1 person the account follows it gains 32.98 followers. A high follower ratio can mean that more people are following @VanlslandHealth out of good will and not through follow-back (Kovshenin), so some further digging is required before a high follower ratio is automatically seen as a success. To achieve this high ratio, we surmise that from an initial low exposure at the 
time the account was created, VanlslandHealth was able to accumulate exposure by tweeting content, mentioning users, retweeting others, and to a lesser extent, following users. These methods acquired some 'reach' (their own followers, and retweeters) and subsequently increased their exposure and reach with each new follower. Over time this would have led to the high follower ratio they have obtained.

\section{Engagement}

'Engagement' is a measure of the number of people interacting with an account through the use of mentions, hashtags, retweets, and links to outside content (Neiger et al. 164). Metrics for engagement can be seen as the number of mentions, rate of retweets, frequency of being favourited, percentage of click-throughs to linked content (polls, surveys, webcasts, online donations to a charity), and frequency of mentions in other tweets.

To begin finding out how to improve the Twitter use in any library, it is critical to discover the level of engagement of your user population with Twitter in the first place. This can be accomplished by locating related groups or institutions with Twitter accounts that engage your user group and then actively engaging these institutions on Twitter. A good example of engagement can be seen in @SunnybrookHSC (see Table II), which mentions one or more followers in 78 of 100 tweets. Hagman notes that addressing users directly using mentions and asking for feedback can increase interest, as users are more likely to continue engaging on their own afterwards (81). This is done in the hope of creating awareness of your organization among their followers, who may then start following you in turn (Hagman 80).

\section{Putting Metrics in Context}

Calculating an organization's metrics using services like Foller.me will not be useful without first considering the strategic goals of the library. It can prove helpful to look at the broader goals of the library and then ask how Twitter might assist in reaching those goals. The monitoring of basic statistics, such as the number of mentions or the number of followers, can be very valuable. However, we recommend taking the time to sit down with stakeholders or administrators and determine which metrics best indicate that your library's social media strategy is doing well. By deciding what the goals are early on and choosing to monitor metrics that correlate with those goals, the researcher will get more meaning from the data, which can then be reported back to those same stakeholders.

For example, if a library wanted to promote services or events, it might choose to measure how often its organization uses specific hashtags when talking about those events. An illustration of this would be to use the tag \#healthfair2012 when tweeting about an annual health fair and then observe if other users also employ that same tag in their own tweets. People will pick up on hashtags relevant to their interests and start using them on their own if they like them. As such, seeing these hashtags in circulation among followers can indicate success in increasing reach and awareness about that 
particular service or event. Being able to demonstrate that a certain number of users were promoting your library's brand through hashtag use or re-tweeting your words in their own tweets is a very powerful piece of evidence. Keeping track of your follower's hashtag use can help your library figure out which hashtags are the most popular and which topics are relevant to your user's interests. This in turn reveals a lot about your exposure and reach.

Twitter is one of the most direct ways of getting access to the most current trends in what your users are thinking. Instead of waiting for surveys to come back, which can take months and require staff time, Twitter offers an instantaneous look at what is going on in the minds of your patrons. As a fascinating example of just how quickly tweets can predict how users are feeling, a system called Infoveillance uses tweets to help disease control agencies anticipate influenza outbreaks. The system uses Twitter to look for hashtags and tweets related to flu symptoms among large groups of users, and has successfully anticipated outbreaks of influenza (Eysenbach 154). This example illustrates how paying attention to Twitter is a great way to anticipate what your users are thinking and how such knowledge can permit a timely response to those needs.

Twitter can be a powerful tool in medicine, but librarians should exercise some caution when using it. Problems can arise if patients start to direct their personal medical questions to a library via its Twitter account. Health consumers may need to be reminded that Twitter is not an appropriate forum for the discussion of personal health issues (Terry 508).

It is not just library patrons that need to be mindful of what they tweet. It can be very easy for a librarian on Twitter to get off topic and start diluting the messages that promote the services that the library selected to target in its Twitter use. The power of social media comes from its ability to "collect and disseminate information quickly among large numbers of people simultaneously" (Hawn 363), however anything published online remains on record even after deletion. In-house policies should always be in place to help direct librarians on how to keep tweets professional and to ensure that the library Twitter account is always promoting the goals and services desired by stakeholders.

Keeping in touch with followers goes beyond just re-tweeting their posts or thanking them when they mention the library or its services. It is also important to use Twitter to ask followers for feedback about what types of information or resources they would like to learn about in the future. A recommended model to follow is the Cleveland Clinic's social media strategy because of their focus on listening to their followers. The clinic conducts semi-annual surveys to ask their followers to list topics of interest and to list which healthcare organizations they follow regularly (Sharp 30). This is an excellent approach because it not only suggests which topics librarians should discuss in the future but also gives librarians the names of other popular health organizations to look to for inspiration and new ideas. Sharp asserts that while counting the number of people following you on Twitter is "useful", it "does not translate into patient engagement or 
satisfaction, much less new business" (31). The Cleveland Clinic's approach also has the advantage of making the clinic appear more accountable to its followers.

Whether the researcher asks followers directly or just monitors their Twitter habits using online tools, it is recommended that a history of the data be kept. User responses and Twitter metrics become more meaningful over extended periods of time. The longer this information is collected, the more likely the researcher will develop a long-term perspective of how the social media mission is doing; when the data suggests that social tools are no longer making positive contributions to the organization, it is best to consider phasing them out (Berryman 170).

A good take away message from current Twitter research is that no single metric or method will automatically prove or disprove the success of an online campaign. Even though Twitter can predict trends to a certain degree, there are also examples of where assumptions about Twitter's predictive powers can be taken too far. For instance, a study by Eysenbach demonstrates that Twitter will not always yield perfect results if one is trying to use tweets to anticipate the success of a newly published academic journal article (Eysenbach, "Can Tweets Predict Citations?"). Applying this same cautionary logic to the context of health libraries Twitter metrics, the success of a service or campaign is not guaranteed simply because people tweet about it. Metrics should be seen as providing supplementary data to gain insight into users, but no single Twitter metric should be used to influence major decisions without first considering the larger context of an organization.

\section{Conclusion}

A lot can be learned by the way doctors, administrators, nurses, and librarians in health organizations use Twitter accounts, and these best practices are important for all health libraries to keep in mind. The goal of this paper was to show how Canadian health librarians can use Twitter more effectively by knowing which metrics to watch and how to collect this data. Based on suggestions from existing research, the authors used the Foller.me service to collect data to show how health libraries and organizations can use Twitter data to gain insight into how they are engaging their users. The data was examined in conjunction with Twitter related research, and ways were suggested for librarians to set concrete goals, choose metrics that relate to those goals, and evaluate their own progress over time. By highlighting different criteria, pointing to best practices, and warning against challenges when working in online environments, the authors hope to encourage health libraries to leverage their use of social media to improve services and make meaningful connections with their patrons.

\section{Works Cited}

Aharony, Noa. "Twitter Use in Libraries: an Exploratory Analysis." Web Librarian 4.4 (2010): 333-50. Web. 26 Jun. 2012. 
Berryman, Donna. "Learning to Drive: Developing a Workable Awareness Plan for Monitoring New Technology." Medical Reference Services Quarterly 29.2 (2010): 166-74. Web. 19 Mar. 2012.

Bosque, Darcy Del, Sam Leif, and Susie Skarl. "Libraries Atwitter: Trends in Academic Library Tweeting." Reference Services Review 40.2 (2012): 199-213. Web. 26 Jun. 2012.

Chretien, Katherine, Justin Azar, and Terry Kind. "Physicians on Twitter." Journal of the American Medical Association 305.6 (2011): 566-68. Web. 28 Mar. 2012.

Cuddy, Colleen, Jamie Graham, and Emily Morton-Owens. "Implementing Twitter in a Health Sciences Library." Medical Reference Services Quarterly 29.4 (2010): 320-30. Web. 31 Mar. 2012.

Eysenback, Gunther. "Can Tweets Predict Citations? Metrics of Social Impact Based on Twitter and Correlation with Traditional Metrics of Scientific Impact."

Journal of Medical Internet Research 13.4 (2011): e123. Web. 14 Mar. 2012.

Eysenbach, Gunther. "Infomediology and Infoveillance Tracking Online Health Information and Cyberbehavior for Public Health." American Journal of Preventative Medicine 40.5 Supplement 2 (2011): S154-58. Print.

Felix, Juan. "Which Social Media Management Tool is Best for your Business." Mirror Yourself. Felix Relationship Marketing Inc., 21 May 2011. Web. 30 Mar. 2012.

Giustini, Dean. "Canadian Health Librarians that Twitter." HLWIKI Canada. 20 Oct. 2009. Web. 25 Jun. 2012.

Giustini, Dean. "List of Canadian Health Libraries." HLWIKI Canada. 18 Aug. 2012. Web. 29 Sept. 2012.

Giustini, Dean. "Social Media Trends for Health Librarians: a Primer on Using Social Media for Clinical Disease Surveillance." Journal of the Canadian Health Libraries Association 33.2 (2012): 92-94. Web. 24 Jun. 2012.

Giustini, Dean and Mary-Doug Wright. "Twitter: an Introduction to Microblogging for Health Librarians." Journal of the Canadian Health Libraries Association 30.1 (2009): 11-17. Web. 31 Mar. 2012.

Hackworth, Brittany and Michelle Kunz. "Health Care and Social Media: Building Relationships via Social Networks." Academy of Healthcare Management Journal 7.2 (2011): 1-14. Web. 19 Mar. 2012. 
Hagman, Jessica. "Joining the Twitter Conversation." Public Services Quarterly 8.1 (2012): 78-85. Web. 25 Jun. 2012.

Hawn, Carleen. "Take Two Aspirin and Tweet Me in the Morning: How Twitter, Facebook, and Other Social Media are Reshaping Health Care." Health Affairs 28.2 (2009): 361-8. Web. 19 Mar. 2012.

Hesse, Bradford, et al. "Trust and Sources of Health Information: the Impact of the Internet and its Implications for Health Care Providers: Findings From the First Health Information National Trends Survey." Archives of Internal Medicine 165.22 (2005): 2618-24. Web. 10 Mar. 2012.

Kovshenin, Konstantin. Foller.Me. Beta. 2009. Web. 30 Mar. 2012.

Neiger, Brad, et al. "Use of Social Media in Health Promotion: Purposes, Key Performance Indicators, and Evaluation Metrics." Health Promotion Practice 13.2 (2012): 159-64. Web. 28 Mar. 2012.

O'Moore-Klopf, Katharine. "Twitter Tweeps." American Medical Writers Association Journal 26.4 (2011): 183-4. Web. 31 Mar. 2012.

"Features." Sprout Social. Sprout Social, 2010. Web. 30 Mar. 2012.

Sarringhaus, Meredith. "The Great Divide: Social Media's Role in Bridging Healthcare's Generational Shift." Journal of Healthcare Management 56.4 (2011): 235-44. Web. 19 Mar. 2012.

Sharp, John. "Brand Awareness and Engagement: a Case Study in Healthcare Social Media." Frontiers of Health Services Management 28.2 (2011): 29-33. Web. 19 Mar. 2012.

Stuart, David. "What are Libraries Doing on Twitter?" Online 34.1 (2010): 45-47. Web. 31 Mar. 2012.

Terry, Mark. "Twittering Healthcare: Social Media and Medicine." Telemedicine and eHealth 15.6 (2009): 507-10. Web. 10 Mar. 2012. 